\title{
Dynamic Performance of Service-manufacturing Hybrid Supply Chain with Two Forecasting Methods
}

\author{
Weiwei Wang ${ }^{1, a}$, Yue Hong ${ }^{1, b}$ and Zaifang Zhang ${ }^{1, c}$ \\ ${ }^{1}$ School of Mechatronic Engineering and Automation, Shanghai University, Shanghai, 200072, \\ China \\ aloveyou@i.shu.edu.cn, ’hongyue@staff.shu.edu.cn, 'zaifangzhang@shu.edu.cn
}

Keywords: Hybrid Supply Chain, Exponential Smoothing Forecasts, Moving Average Forecasts, Dynamic Response.

\begin{abstract}
This paper deals with the study of the dynamic performance of service-manufacturing hybrid supply chain with different forecasting methods. Two forecasting methods in two-echelon hybrid supply chain system are exponential smoothing forecasts (ESF) and moving average forecasts (MAF). Based on Automatic Pipeline Inventory and Order Based Production Control System (APIOBPCS), the Automatic Pipeline Control System of Production and Service in Hybrid Supply Chain (APIOBPSCS) is built using control theory. On this basis, the dynamic responses of two hybrid supply chain systems under step demand input are analyzed by simulation. As the system parameters change, two kinds of hybrid supply chains with different forecasting methods are compared in the performance, the fluctuations of product order rate, works in process (WIP), and actual inventory of product and service pile-up rate. Simulation result shows that the overall influence of hybrid supply chain should be considered according to the different forecasting methods. With selecting corresponding forecasting methods, the reasonable system parameters will be set to improve the overall operation efficiency of hybrid supply chain system.
\end{abstract}

\section{Introduction}

Service-manufacturing is a new manufacturing mode that manufacturing and service are integrated in [1]. The hybrid supply chain of the service-manufacturing is a blend of product supply chain and service supply chain, that is to say, service flow and material flow are existing at the same time. In hybrid supply chain, we focus on customer demand and provide the customers with a range of associated services through the lifecycle of products [2]. Hence, the hybrid supply chain is combined of customers, service providers and product suppliers. Based on BM enterprise, the two-echelon hybrid supply chain is shown in the Fig.1.

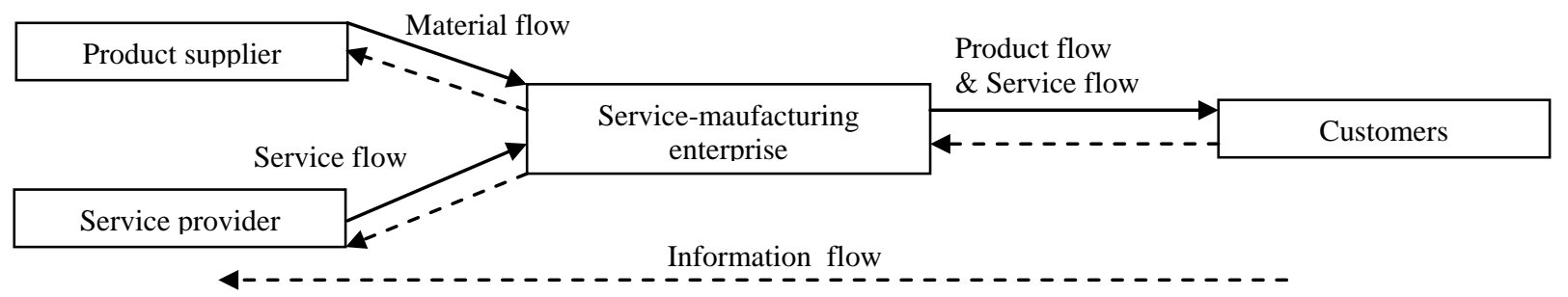

Fig. 1 Two-echelon service-manufacturing hybrid supply chain model

Transfer function techniques are particularly powerful methods of systems analysis in discrete time. Adelson used z-transforms of second-order exponential smoothing forecasting algorithms within an inventory- and order- based production control system [3]. John et al. created the APIOBPCS (Automatic Pipeline Inventory and Order Based Production Control System) model that was studied using Laplace transforms and block diagrams [4]. Disney et al. conducted an analysis of APIOBPCS in discrete time using the transfer function techniques [5].

On the basis of the existing research results, we build hybrid supply chain system which is the Automatic Pipeline Inventory and Order Based Production and Service Control System (APIOBPSCS) according to the actual circumstance of BM's supply chain. 


\section{The Model of Hybrid Supply Chain Systems with Two Forecasting Methods}

In this paper, we develop the research based on the following hypotheses:

- Hybrid supply chain system is linear.

- Market demand can be stable, or can be discrete.

- Products and services are made to order.

- Each product corresponds to one service.

- The upstream of supply chain (providers) always fulfils the demand of the downstream (end user).

Fundamental Principle. The APIOBPSCS structure can be expressed in words as "Let the production targets be equal to the sum of demand forecasts (exponential smoothing forecasts over $T_{d}$ time units, moving average forecasts over $T_{m}$ time units), plus a fraction ( $1 / T_{i}$ ) of the inventory error between actual inventory and target inventory, plus a fraction $\left(1 / \mathrm{T}_{\mathrm{w}}\right)$ of the WIP error between actual WIP and target WIP. And let the services targets be equal to the fraction $\left(1 / T_{a}\right)$ of the service error between service demand of customer and actual ability to dispose of". The verbal description can be turned into a causal loop diagram as shown in Fig.2.

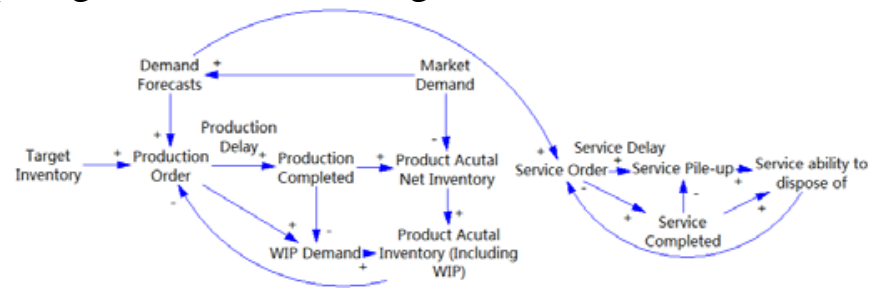

Fig. 2 The causal loop diagram of APIOBPSCS system

Forecasting Methods and Transfer Functions. It is useful at this stage to describe the forecasting policy of the APIOBPSCS model that is shown in Fig.3. The forecasting policy uses ESF and MAF respectively. The difference equation of the forecasting policy using ESF is shown in equation (1).

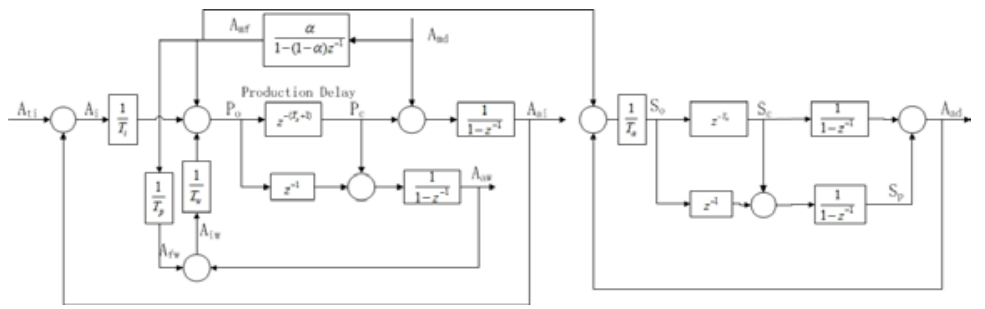

Fig. 3 The block diagram representation of APIOBPSCS system

$$
\mathrm{A}_{\mathrm{mft}}=\mathrm{A}_{\mathrm{mft}-1}+\frac{1}{1+\mathrm{T}_{\mathrm{d}}}\left(\mathrm{A}_{\mathrm{mft}}-\mathrm{A}_{\mathrm{mdt}-1}\right)
$$

The z-transform of the ESF is given by equation (2). We can link the smoothing constant $\alpha$ in the $\mathrm{z}$-transform to $\mathrm{T}_{\mathrm{d}}$ in the difference equation using the EXSMO relationship established by Towill [6].

$$
\mathrm{A}(\mathrm{z})=\frac{\alpha}{1-\mathrm{z}^{-1}(1-\alpha)}
$$

The transfer functions of hybrid supply chain system using ESF are shown in equations (3) to (6).

$$
\begin{aligned}
& \frac{P_{o}}{A_{m d}}=\frac{z^{T p+1} \times\left(T_{i} z-T_{i}+T_{p} T_{w} z-T_{d} T_{p} T_{w}-T_{i} T_{p} T_{w}+T_{d} T_{p} T_{w} z+T_{i} T_{p} T_{w} z\right)}{\left.T_{p}\left(T_{w}\left(T_{i} z^{T} p_{(} z-1\right)+1\right)-T_{i}+T_{i} z^{T} p\right)\left(z-T_{d}+T_{d} z\right)} \\
& \frac{A_{a w}}{A_{m d}}=\frac{z\left(z^{T} p-1\right)\left(T_{p} T_{w}\left(z-T_{d}+T_{d} z\right)+T_{i}(z-1)\left(1+T_{p} T_{w}\right)\right)}{T_{p}(z-1)\left(z-T_{d}+T_{d} z\right)\left(T_{i}\left(z^{T} p_{-} T_{w} z^{T} p_{T}+T_{w} z^{T} p^{+1}-1\right)+T_{w}\right)}
\end{aligned}
$$

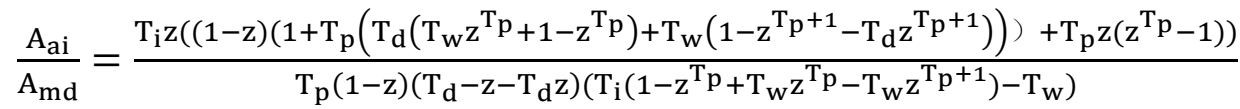




$$
\frac{S_{p}}{A_{m d}}=\frac{z^{T_{o}+1}-z^{2}}{z^{T_{o}}\left(T_{a}(z-1)+1\right)\left(z-T_{d}+T_{d} z\right)}
$$

When using the MAF in hybrid supply chain system, the difference equation of the forecasting policy can be seen in equation (7). And the z-transform of the MAF is given by equation (8).

$$
\begin{aligned}
& A_{m f t}=\frac{\sum_{i=0}^{T_{m}-1} A_{m d t-i}}{T_{m}} \\
& A(z)=\frac{1-z^{-T_{m}}}{T_{m}\left(1-z^{-1}\right)}
\end{aligned}
$$

Similarly rearranging the hybrid supply chain system for product order rate, WIP, actual inventory of product and service pile-up rate, we can get the following discrete time transfer functions:

$$
\begin{aligned}
& \frac{P_{o}}{A_{m d}}=\frac{z^{T_{p}+1}\left(T_{i}\left(z^{T}-1\right)\left(1+T_{p} T_{w}\right)+T_{m} T_{p} T_{w} z^{T}\right)}{T_{m} T_{p} z^{T} m\left(T_{i} T_{w} z^{T} p(z-1)+T_{w}-T_{i}+T_{i} z^{T} p\right)} \\
& \frac{A_{a w}}{A_{m d}}=\frac{z\left(z^{T} p-1\right)\left(T_{m} T_{p} T_{w} z^{T}+T_{i}\left(z^{T} m-1\right)\left(1+T_{p} T_{w}\right)\right)}{T_{m} T_{p} z^{T} m\left((z-1)\left(T_{i}\left(z^{T} p_{-1}\right)+T_{w}\left(1-T_{i} z^{T} p_{1}+T_{i} z^{T} p^{+1}\right)\right)\right)} \\
& \frac{A_{a i}}{A_{m d}}=\frac{T_{i} z\left(\left(z^{T}-1\right)\left(1+T_{p} T_{w}\right)+T_{m} T_{p} z^{T} m_{\left(1-z^{T}\right.} p_{+} T_{w} z^{T} p_{(1-z))}\right.}{T_{m} T_{p} z^{T} m(z-1)\left(T_{w}+T_{i}\left(z^{T} p_{-1} T_{w} z^{T} p_{(z-1)}\right)\right)} \\
& \frac{S_{p}}{A_{m d}}=\frac{z\left(z^{T_{o}}-z\right)\left(z^{T_{m}-1}\right)}{T_{m} z^{T_{m}+T_{o}(z-1)\left(T_{a} z-T_{a}+1\right)}}
\end{aligned}
$$

\section{Comparing the dynamic response of the APIOBPSCS systems with two forecasting methods}

According to the transfer functions of the APIOBPSCS systems, we can utilize Matlab for simulation to illustrate the dynamic response of the systems using ESF and MAF respectively. This insight allows us to characterize the step response with two descriptors that are Peak value (or overshoot) and settling time [7]. Peak value (or overshoot) is used to observe the system stationary, and the settling time is deemed as the demonstration of system rapid response. In order to make a fair comparison between ESF and MAF, we have to set [8]:

$$
\alpha=\frac{2}{\mathrm{~T}_{\mathrm{m}}+1} \text { or } \mathrm{T}_{\mathrm{m}}=2 \mathrm{~T}_{\mathrm{a}}+1
$$

In this paper, if it is not special to note, the parameters are set from BM database as the following value: $\mathrm{T}_{\mathrm{p}}=1 ; \mathrm{T}_{\mathrm{i}}=\mathrm{T}_{\mathrm{w}}=4, \mathrm{~T}_{\mathrm{d}}=8, \mathrm{~T}_{\mathrm{a}}=1, \mathrm{~T}_{\mathrm{o}}=2, \mathrm{~T}_{\mathrm{m}}=17$.

Step Responses. The step responses of product order rate, WIP, actual inventory of product and service pile-up rate in two kinds of systems are compared as plotted and shown in Fig.4.
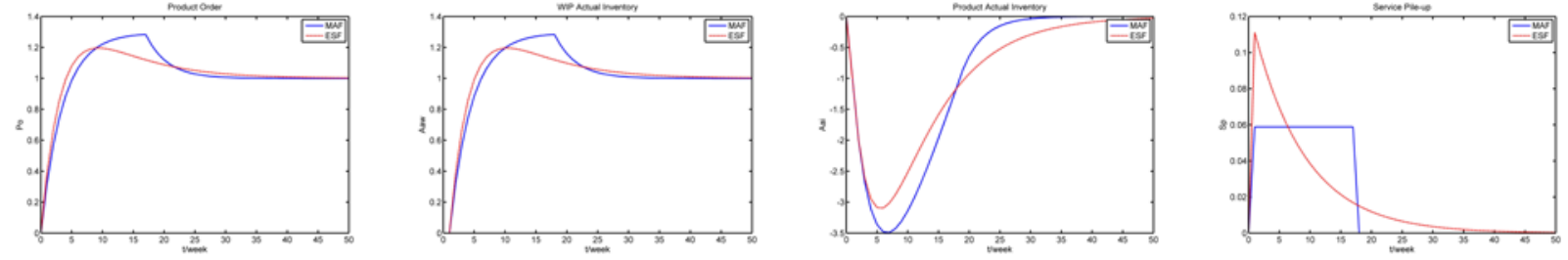

Fig. 4 Step responses of the APIOBPSCS systems with two forecasting methods

Parameters Influences. The variance of parameters make different effects on the dynamic performance of the APIOBPSCS system using MAF and ESF. Note that the parameters considered in this paper are $T_{w}, T_{i}, T_{p}, T_{o}$ and $T_{a}$. When we change one parameter value each time, the other parameters remain the same. The simulation results of the influences on the dynamic responses in the systems are made clear in Fig. 5 to Fig.12. Note that we compare the overshoots of APIOBPSCS systems when observing the influences on the product order rate and WIP actual inventory as $\mathrm{T}_{\mathrm{p}}$ 
change, because of the fact that steady-state values of product order rate and WIP actual inventory is not equal to 1 , but change as $T_{p}$ change.
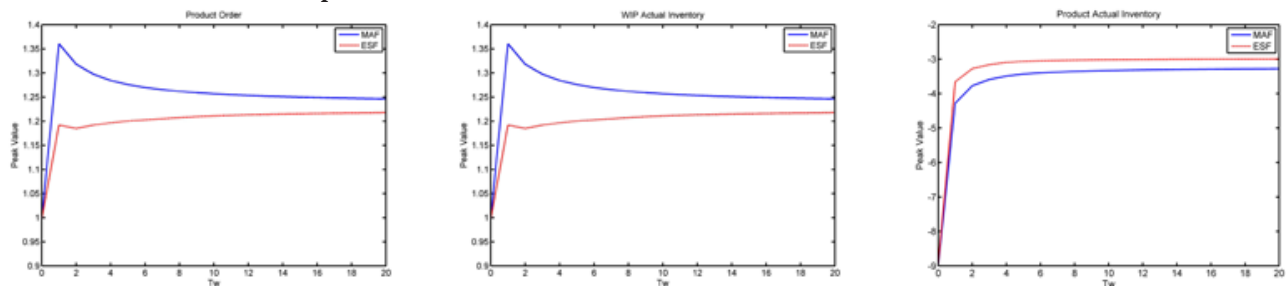

Fig. 5 Peak value variation of the dynamic response in APIOBPSCS system as $\mathrm{T}_{\mathrm{w}}$ change
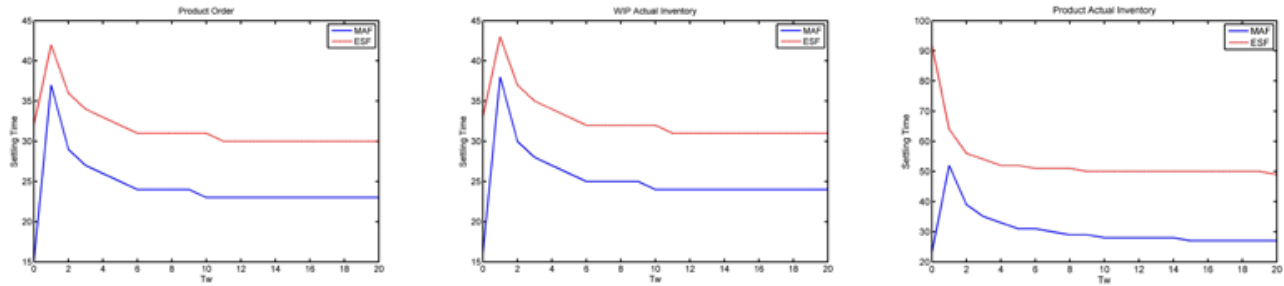

Fig. 6 Settling time variation of the dynamic response in APIOBPSCS system as $\mathrm{T}_{\mathrm{w}}$ change
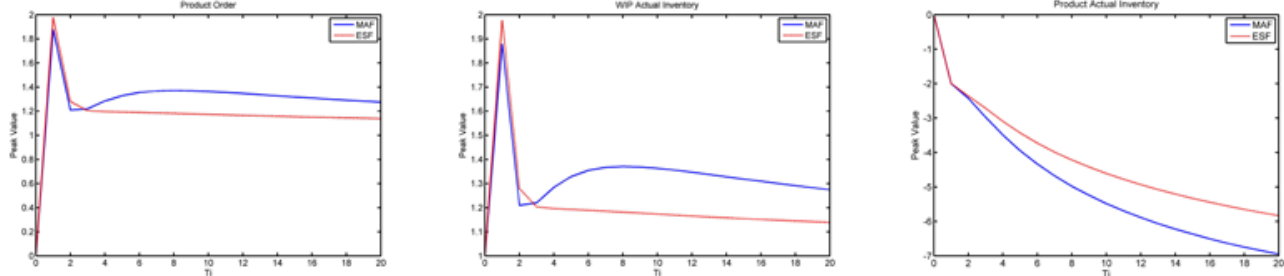

Fig. 7 Peak value variation of the dynamic response in APIOBPSCS system as $\mathrm{T}_{\mathrm{i}}$ change
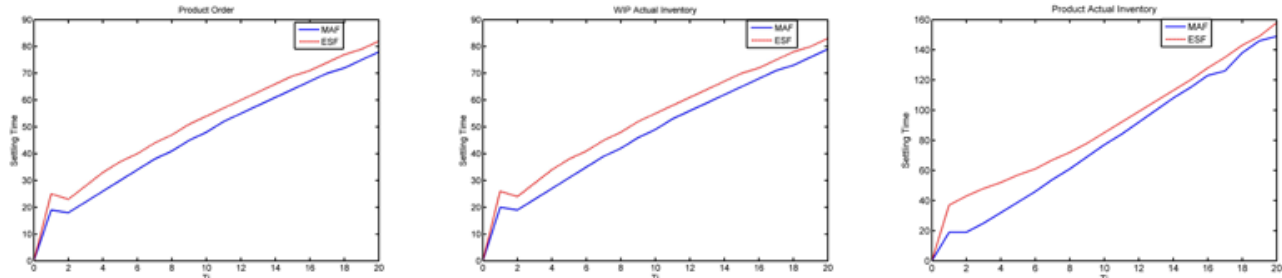

Fig. 8 Settling time variation of the dynamic response in APIOBPSCS system as $\mathrm{T}_{\mathrm{i}}$ change
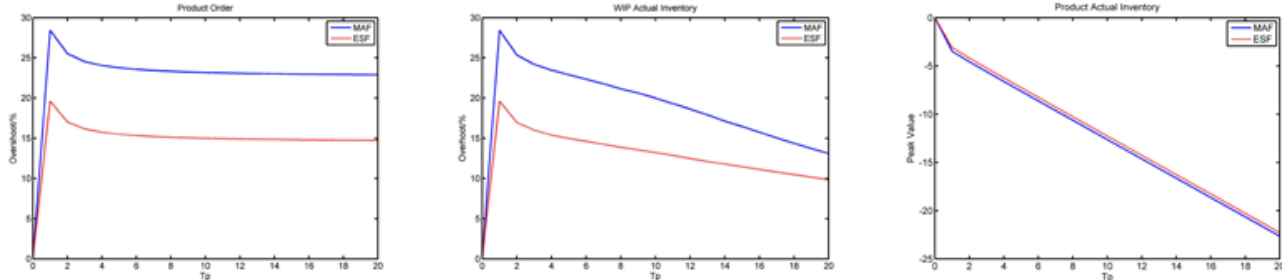

Fig. 9 Overshoot (or Peak Value) variation of the dynamic response in APIOBPSCS system as $\mathrm{T}_{\mathrm{p}}$ change
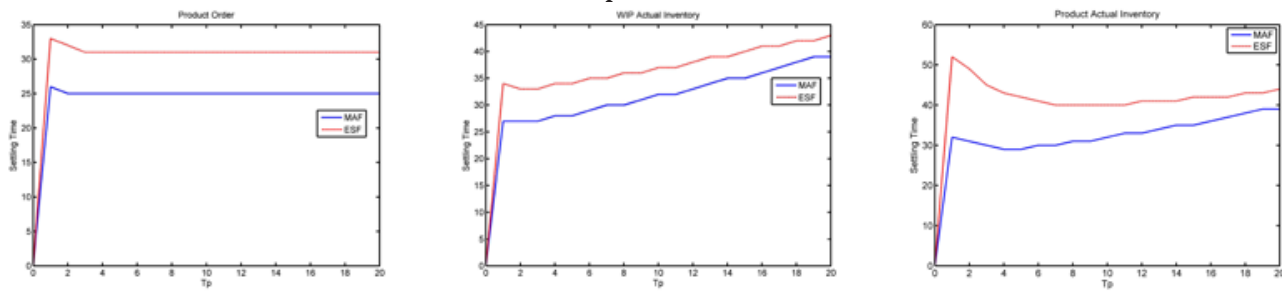

Fig. 10 Settling time variation of the dynamic response in APIOBPSCS system as $T_{p}$ change 

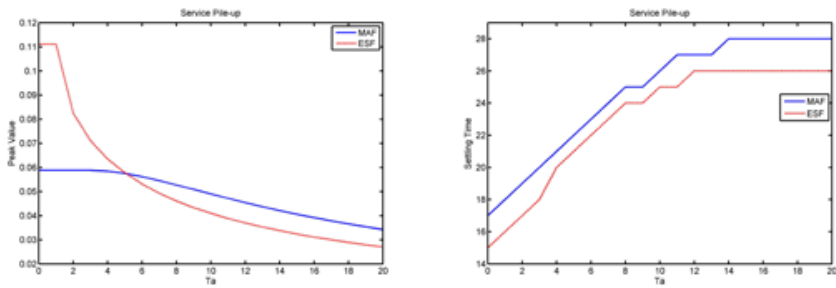

Fig. 11 Peak value and settling time variation of the dynamic response in APIOBPSCS system as $\mathrm{T}_{\mathrm{a}}$ change
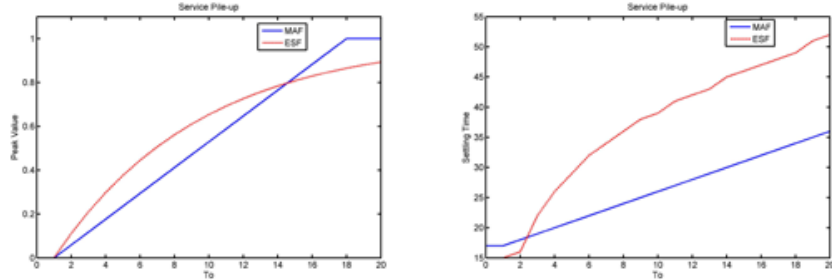

Fig. 12 Peak value and settling time variation of the dynamic response in APIOBPSCS system as $\mathrm{T}_{\mathrm{o}}$ change

To sum up, the influences of the system dynamic responses as parameters change are synthetically considered deriving the comparison table of the dynamic performances in two kinds of APIOBPSCS systems. This is shown in Table 1. Furthermore, '>' means 'better', for example if 'ESF $>\mathrm{MAF}$ ', it means ESF is better than MAF.

Table 1 The comparison of dynamic performances in two APIOBPSCS systems using ESF and MAF

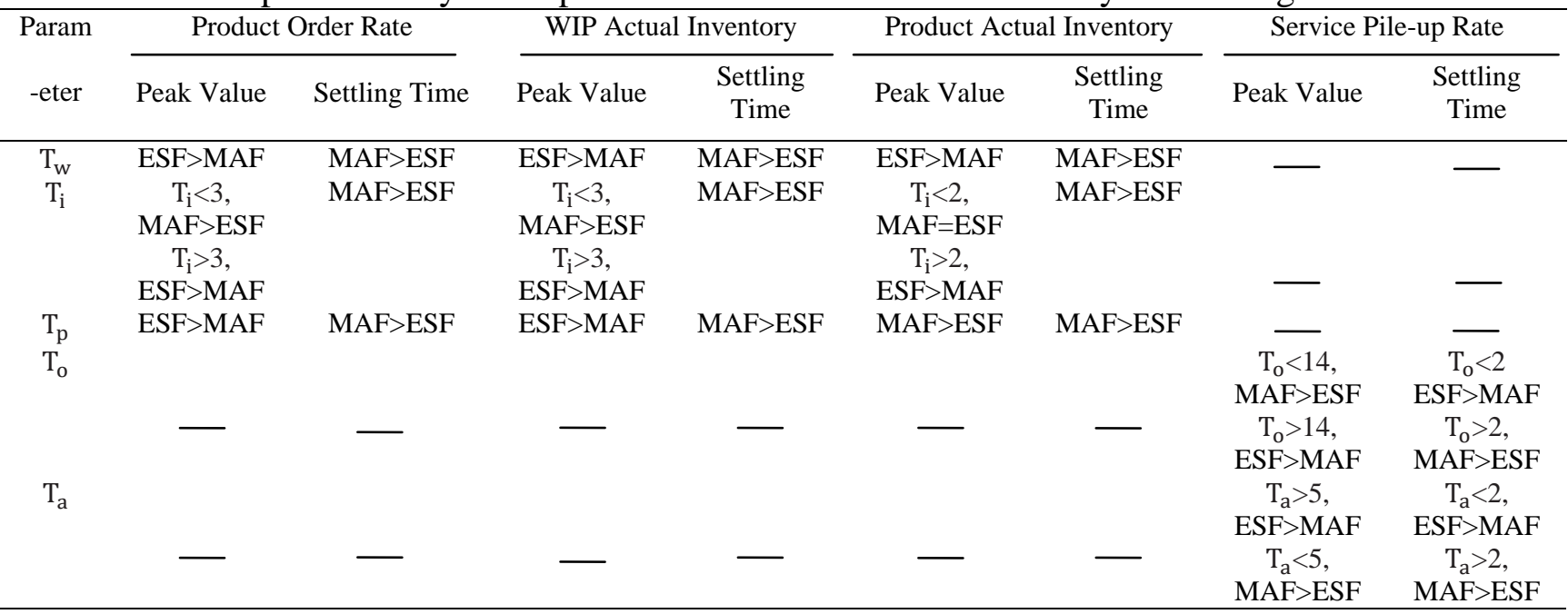

\section{Conclusions}

Under step input, as the value of $\mathrm{T}_{\mathrm{o}}$ and $\mathrm{T}_{\mathrm{a}}$ are bigger, the peak value of the APIOBPSCS systems using ESF and MAF is larger whilst the settling time is longer. Thus, BM enterprise can reduce the service order lead-time and adjustment time of ability to dispose of to decrease service pile-up and meet more customer demand. The parameters of $T_{w}$, $T_{i}$ and $T_{p}$ make different influence on the peak value (or overshoot) and settling time in systems so that BM enterprise primarily consider the stationary or rapid response of system according to the overall goal of hybrid supply chain.

For the forecasting methods, the rapid response of the APIOBPSCS system using MAF is effectively better than the system using ESF. But the stationary of system using MAF is worse than the system using ESF. This is concluded that we cannot give consideration to both stationary and rapid response. Therefore, the dynamic response and parameters influence are synthetically considered to propound the strategy of service- manufacturing hybrid supply chain in order to provide professional service of hybrid supply chain. 


\section{Appendix A: General Terms}

APIOBPCS Automatic Pipeline Inventory and Order Based Production Control System,

ESF Exponential Smoothing Forecasts,

MAF Moving Average Forecasts,

APIOBPSCS Automatic Pipeline Inventory and Order Based Production and Service Control System,

WIP Work In Process.

\section{Appendix A: APIOBPSCS Terms}

\begin{tabular}{rlrl}
\hline Term & Description & Term & Description \\
\hline $\mathrm{A}_{\mathrm{ti}}$ & Target Inventory & $\mathrm{A}_{\mathrm{sd}}$ & Service Demand \\
$\mathrm{A}_{\mathrm{ai}}$ & Actual Inventory & $\mathrm{A}_{\mathrm{sf}}$ & Service Forecast \\
$\mathrm{A}_{\mathrm{mf}}$ & Market Forcast & $\mathrm{A}_{\mathrm{ad}}$ & Service Ability to Dispose of \\
$\mathrm{A}_{\mathrm{md}}$ & Market Demad & $\mathrm{S}_{\mathrm{o}}$ & Service Order Delayed \\
$\mathrm{P}_{\mathrm{o}}$ & Product Order Rate & $\mathrm{S}_{\mathrm{c}}$ & Service completion \\
$\mathrm{P}_{\mathrm{c}}$ & Product completion Rate & $\mathrm{S}_{\mathrm{p}}$ & Service pile-up rate \\
$\mathrm{A}_{\mathrm{aw}}$ & Acutal WIP & $\mathrm{T}_{\mathrm{a}}$ & Adjustment Time of Ability to Dispose of \\
$\mathrm{A}_{\mathrm{fw}}$ & WIP Forecasting & $\mathrm{T}_{\mathrm{o}}$ & Order Lead-time \\
$\mathrm{A}_{\mathrm{iw}}$ & WIP Inventory & $\alpha$ & $1 /\left(1+\mathrm{T}_{\mathrm{a}}\right)$ \\
$\mathrm{T}_{\mathrm{i}}$ & Inventory Adjustment Time & $\mathrm{T}_{\mathrm{m}}$ & Number of periods used in the moving average \\
$\mathrm{T}_{\mathrm{p}}$ & Production Lead-time & $\mathrm{t}$ & time \\
$\mathrm{T}_{\mathrm{w}}$ & WIP Adjustment Time & $\mathrm{z}$ & z-transform operator \\
$\mathrm{T}_{\mathrm{d}}$ & Average age of exponential smoothing forecast & & \\
\hline
\end{tabular}

\section{References}

[1] Linyan Sun, Gang Li, Zhibin Jiang et al. Advanced manufacturing mode in the 21st century Service-oriented manufacturing. [J]. The Chinese mechanical engineering, 2007,18(19): 23072312.

[2] Johnson, M., Mena, C. Supply chain management for servitised products: A multi-industry case study[J]. International journal of production economics,2008.114(1):p.27-39.

[3] Adelson, R.M, The dynamic behaviour of linear forecasting and scheduling rules[J]. Operational Research Quarterly, 1996,17(4):447-462.

[4] John, S., Naim, M.M. and Towill, D.R., Dynamic analysis of a WIP compensated decision support system[J]. International Journal of Manufacturing System Design, 1994, 1(4) :283-297.

[5] Stephen M. Disneya, Denis R. Towilla and Roger D.H. Warburtonb, On the equivalence of control theoretic, differential, and difference equation approaches to modeling supply chains[J]. International Journal of Production Economics,2006, 101(1):194-208.

[6] Towill, D.R., Exponential smoothing of learning curve data [J]. International Journal of Production Research, 1977,15(1):1-15.

[7] Disney S M, Towill D R, Warburton R D H. On the equivalence of control theoretic, differential, and difference equation approaches to modeling supply chains[J]. International Journal of Production Economics,2006.101: 194-208.

[8] Dejonckheere, J., Disney, S.M., Lammbrecht, M.R. et al. Measuring and avoiding the bullwhip effect: a control theoretic approach[J]. European Journal of Operation Research, 2003.147(3): 567-590. 